\title{
Emergency treatment of ophthalmologic diseases during the first phase of SARS-CoV2 pandemic in a tertiary referral center in Germany - the COVID- DETOUR questionnaire study
}

Christoph Ehlken ( $\square$ christoph.ehlken@uksh.de)

Eye Center, Medical Center, Faculty of Medicine, University of Kiel, Germany https://orcid.org/00000001-7388-7173

\section{Constantin von Medem}

Universitatsklinikum Schleswig-Holstein Campus Kiel Klinik für Ophthalmologie (Augenheilkunde): Universitatsklinikum Schleswig-Holstein Campus Kiel Klinik fur Ophthalmologie (Augenheilkunde)

\section{Maya Lüdemann}

Universitatsklinikum Schleswig-Holstein Campus Kiel Klinik für Ophthalmologie (Augenheilkunde): Universitatsklinikum Schleswig-Holstein Campus Kiel Klinik fur Ophthalmologie (Augenheilkunde)

\section{Anna Maria Barbara Kirsch}

Augenklinik Klinikum Kassel GmbH

\section{Johann Baptist Roider}

Universitatsklinikum Schleswig-Holstein Campus Kiel Klinik für Ophthalmologie (Augenheilkunde): Universitatsklinikum Schleswig-Holstein Campus Kiel Klinik fur Ophthalmologie (Augenheilkunde)

\section{Research article}

Keywords: COVID, emergency, pandemic, delay in treatment

Posted Date: March 18th, 2021

DOl: https://doi.org/10.21203/rs.3.rs-330204/v1

License: (c) (i) This work is licensed under a Creative Commons Attribution 4.0 International License.

Read Full License

Version of Record: A version of this preprint was published at BMC Ophthalmology on August 16th, 2021. See the published version at https://doi.org/10.1186/s12886-021-02054-7. 


\section{Abstract}

Background:

During the first wave of the COVID-19 pandemic, the need of treatment of urgent ophthalmological diseases and the possible risk of a SARS-CoV-2 infection had to be weighed against each other. In this questionnaire study, we aimed to analyze potential barriers and patients' health beliefs during and after the lockdown early 2020 in a tertiary referral center in Kiel, Germany.

Methods:

Patients admitted for the treatment of urgent ophthalmic diseases between March $1^{\text {st }}, 2020$, and June $3^{\text {rd }}, 2020$, were asked to participate in a questionnaire study. After informed consent was obtained, patients were interviewed using a standardized questionnaire which addressed aspects of their medical history, their health beliefs concerning the COVID-19 pandemic and barriers on their way to the treatment center. The study group was subdivided into two subgroups, depending on the occurrence of their symptoms, before and after the lockdown was ended on April $20^{\text {th }}, 2020$.

Results:

Ninety-three patients were included, 43 in subgroup A (before April $20^{\text {th }}$ ) and 50 in subgroup B (April $20^{\text {th }}$ or later). Retinal disorders were most common (approximately $60 \%$ ), with retinal detachments being the most singular reason for admission. Only 8 patients (8.6\%) experienced a delay between their decision to visit a doctor until the actual examination. Every fourth patient was afraid of a COVID-19 infection, and expected a higher likelihood for an infection at the hospital. Patients with comorbidities tended to be more likely to be afraid of an infection (correlation coefficient $0.183, p=0.0785$ ) and were significantly more likely to be concerned about problems with organizing follow-up care (corr. coefficient 0.222 , $p=0.0328$ ). Higher age was negatively correlated with fear of infection (corr. coefficient $-0.218, p$-value $0.034)$.

Conclusion:

In this questionnaire study, only a minority of patients indicated a delay in treatment, regardless of whether symptoms occurred before or after the lockdown before April $20^{\text {th }}$. While patients with comorbidities were more concerned about infection and problems during follow-up care, patients of higher age - who have a higher mortality - were less afraid. Protection of high-risk groups should be prioritized during the SARS-CoV-2 pandemic.

Trial registration:

The study was registered as DRKS00021630 at the DRKS (Deutsches Register Klinischer Studien) before the conduction of the study on May $5^{\text {th }}, 2020$. 


\section{Key Messages}

- Several studies reported the underutilization of emergency units during the first phase of the SARSCoV-2 pandemic in 2020, resulting delayed diagnosis and treatment with more progressed stages of disease, e.g. in patients with retinal detachment.

- In this questionnaire study, only a minority of patients indicated delays from symptoms to ophthalmological examination or treatment in our tertiary referral center in Germany.

- More than every fourth patient was concerned of a COVID-19 infection. While patients with comorbidities were more concerned, older patients - though being at a higher risk for severe course of a COVID disease - were less afraid of an infection.

\section{Background}

In early 2020, the SARS-CoV-2 (severe acute respiratory syndrome, coronavirus 2) spread quickly across the globe. After first being described in a local outbreak in Wuhan, China, in December 2019, it was soon detected in multiple countries and declared a pandemic by the WHO on March 11th, 2020. As of March 2021, more than 110 million infections and 2.5 million deaths related to COVID-19, the disease caused by SARS-CoV-2, were counted in 191 countries. It caused considerable uncertainty among all parts of society. Governments had to restrict liberties, health care providers were burdened with the task to prioritize access to the health system, while patients had to decide if their symptoms required urgent diagnosis or therapy.

In Europe, Italy was heavily affected in early 2020 , with a health care system on the brink of decompensation, when intensive care units operated at full capacity only 6 weeks after the first confirmed case $(1,2)$. Reports by Italian scientists helped other countries estimate risks and establish protocols for dealing with the expected increase of COVID patients. Multiple countries went into lockdown, though exact guidelines differed between and even within countries.

Similar to other medical areas, ophthalmologic societies published recommendations for prioritizing examinations and surgery, such as the American Academy of Ophthalmology (https://www.aao.org/headline/list-of-urgent-emergent-ophthalmic-procedures), or the Royal College of Ophthalmologists in the UK (http://rcophth.ac.uk/about/rcophth-guidance-on-restoring-ophthalmologyservices/). Updated guidelines were suggested in order to prevent unnecessary visits on the one hand, but ensure adequate therapy on the other (3). Due to the proximity of patient and doctor during the examination, ophthalmologists (as well as dentists and otolaryngologists) are considered to have a higher risk of infection compared to other disciplines. In a survey among German ophthalmologists, $80 \%$ considered themselves to be at a high risk for a COVID-19 infection (4).

In Germany, the first case of COVID-19 was confirmed on January 24th, 2020. Southern federal states were affected earlier and more severely compared to the northern ones. Federal guidelines concerning the intensity of a general lockdown and the feasibility of elective surgery therefore differed between states. A 
questionnaire study of 1190 health care professionals in Germany reported, that during the first wave of COVID-19 (approximately mid-March to mid-April) patient numbers were reduced to approximately $30 \%$ of pre-pandemic levels, and hospital beds were reserved for emergency patients in $70 \%$ of the participating centers (5). However, less patients with ophthalmic emergencies, such as rhegmatogenous retinal detachment (RRD), perforating trauma, central retinal arterial occlusion or acute ischemic optic neuropathy were admitted. The respondents stated that those lower numbers were caused by institutional guidelines (e.g. only emergencies accepted), but also by cancellation of appointments by the patients.

In this study, we aimed to investigate the patients' perspective of delays and barriers in diagnosis and/or treatment of ophthalmologic emergencies due to COVID-19 in a referral tertiary university hospital in northern Germany.

\section{Methods}

\section{Patient eligibility and recruitment}

Patients were eligible, if the following predefined criteria were met: patient signed informed consent form; patient presented with a symptomatic and acute ophthalmological disease; the disease required treatment as an inpatient; the patient was admitted to the ward between March 1st and June 3rd 2020.

During the prospective phase (May 7th to June 3rd), informed consent was confirmed during the stay at the hospital and the questionnaire was completed with the help of a member of the study group. Patients admitted between March 1st and May 6th (retrospective phase) were identified using an automatic search in the hospital's electronic charts. Patients' charts were manually reviewed regarding the diagnosis and emergency admissions were identified. Suitable patients were informed of the study by telephone or during planned control examinations.

After informed consent was given, the questionnaire was completed with the help of a member of the study group.

Telephone interviews were performed by the same interviewer (Josefin Kohn) between June 9th and September 30th, 2020. The questionnaire has been created for this study and has not been published before. The questionnaire is provided in the additional files.

\section{Questionnaire layout}

The questionnaire addressed different areas concerning the diagnosis, time frames (from the patients' symptoms to a first contact with a referral ophthalmologist or general physician until the time of hospital admission), patients' attitude towards personal risk factors, barriers and fear of infection, and medical history. For questions answered with likert scales, a score of 3 or more ("in part", "mostly agree" "totally agree") was considered as indicative for a subjective burden. The questionnaire is provided as electronic supplementary information (see online resource 1 ). 


\section{Dynamics of recommendations for elective and emergency treatment}

In the study center, recommendations for treatment of elective patients changed during the course of the pandemic. Early March 2020, it was decided to delay any elective surgery. Starting April 20th, 2020, admission of elective patients was again allowed, following the university hospitals recommendations. To reflect this dynamic, the study group was subdivided into two subgroups (before April 20th, 2020, and after).

\section{Statistical Analysis}

Descriptive statistics were used to describe the study groups. Values are displayed as mean and standard deviation or number and percentages, respectively. For comparison between groups, t-test was used for continuous variables, Mann-Whitney-U test and Wilcoxon test were used where appropriate. Fisher's exact test was used to compare discrete variables. Spearman correlation was used to analyze correlation of nonparametric variables.

Statistical analysis was performed using R 4.03 (6) and the EZR package (7). P values of $<0.05$ were considered statistically significant.

\section{Results}

\section{Study group}

One-hundred and seven patients signed informed consent. Of those, 59 were prospectively recruited and 48 were retrospectively included. 10 patients in the retrospective group were not available for the telephone interview and excluded from analysis. Additionally, 4 patients ( 2 in prospective group, 2 in retrospective group) were excluded, as the interview revealed that they were not symptomatic or treated as emergency patients. Consequently, 93 questionnaires (57 prospective, 36 retrospective) were included in the study. Demographics of the study group and subgroups are shown in Table 1.

Table 1

study group demographics

\begin{tabular}{|lllll|}
\hline & total study group & before April 20th & from April 20th & p-value \\
\hline group size & 93 & 43 & 50 & \\
\hline age & $65,3+/-13,9$ & $65,6+/-13,8[30 ; 94]$ & $65,0+/-14,1[23 ; 88]$ & 0,8314 \\
\hline female & $43(46,2 \%)$ & $23(53,5 \%)$ & $20(40,0 \%)$ & 0,216 \\
\hline
\end{tabular}

In general, retinal disorders with more than $60 \%$ of cases were the most common cause leading to hospital admission, followed by corneal infections. Retinal detachment was the most prominent singular 
cause for emergency treatment. Diseases leading to admission are shown in Table 2.

Table 2: diseases leading to hospital admission. 


\begin{tabular}{|c|c|c|c|c|c|}
\hline Area & Diagnosis & ICD-10 code & $\begin{array}{l}\text { total } \\
\text { study } \\
\text { group } \\
\text { no. (\% } \\
\text { of all) }\end{array}$ & $\begin{array}{l}\text { before } \\
\text { April } \\
\text { 20th }\end{array}$ & $\begin{array}{l}\text { from } \\
\text { April } \\
20 \text { th }\end{array}$ \\
\hline \multirow[t]{6}{*}{$\begin{array}{l}\text { retinal } \\
\text { disorders }\end{array}$} & all & & $\begin{array}{l}58 \\
(62.4 \%)\end{array}$ & $\begin{array}{l}26 \\
(60.5 \%)\end{array}$ & $\begin{array}{l}32 \\
(64.0 \%)\end{array}$ \\
\hline & retinal detachment & $\begin{array}{l}\text { H33.0, H33.3, } \\
\text { H33.4 }\end{array}$ & $\begin{array}{l}39 \\
(41.9 \%)\end{array}$ & $\begin{array}{l}19 \\
(44.2 \%)\end{array}$ & $\begin{array}{l}20 \\
(40.0 \%)\end{array}$ \\
\hline & subretinal hemorrhage / AMD & $\mathrm{H} 35.30$ & $\begin{array}{l}2 \\
(2.2 \%)\end{array}$ & $\begin{array}{l}1 \\
(2.3 \%)\end{array}$ & $\begin{array}{l}1 \\
(2.0 \%)\end{array}$ \\
\hline & endophthalmitis & $\mathrm{H} 44.1$ & $\begin{array}{l}4 \\
(4.3 \%)\end{array}$ & $\begin{array}{l}1 \\
(2.3 \%)\end{array}$ & $\begin{array}{l}3 \\
(6.0 \%)\end{array}$ \\
\hline & $\begin{array}{l}\text { vessel disorders: RVO / RAO / } \\
\text { macroaneursym with subretinal } \\
\text { hemorrhage }\end{array}$ & $\begin{array}{l}\text { H34.0, H34.1, } \\
\text { H34.2, H34.8, } \\
\text { H35.6 }\end{array}$ & $\begin{array}{l}12 \\
(12.9 \%)\end{array}$ & $\begin{array}{l}4 \\
(9.3 \%)\end{array}$ & $\begin{array}{l}8 \\
(8.0 \%)\end{array}$ \\
\hline & macular hole & H35.38 & $\begin{array}{l}1 \\
(1.1 \%)\end{array}$ & $\begin{array}{l}1 \\
(2.3 \%)\end{array}$ & 0 \\
\hline \multirow[t]{3}{*}{$\begin{array}{l}\text { corneal } \\
\text { disorders }\end{array}$} & all & & $\begin{array}{l}13 \\
(14.0 \%)\end{array}$ & $\begin{array}{l}7 \\
(16.3 \%)\end{array}$ & $\begin{array}{l}6 \\
(12.0 \%)\end{array}$ \\
\hline & keratitis, ulcus & $\begin{array}{l}\mathrm{H} 16.0, \mathrm{H} 16.2 \\
\mathrm{H} 16.3, \mathrm{H} 19.1 \\
\mathrm{~B} 02.3, \mathrm{H} 19.2\end{array}$ & $\begin{array}{l}12 \\
(12.9 \%)\end{array}$ & $\begin{array}{l}6 \\
(14.0 \%)\end{array}$ & $\begin{array}{l}6 \\
(12.0 \%)\end{array}$ \\
\hline & corneal transplant failure & T86.83 & $\begin{array}{l}1 \\
(1.1 \%)\end{array}$ & $\begin{array}{l}1 \\
(2.3 \%)\end{array}$ & 0 \\
\hline \multirow[t]{4}{*}{$\begin{array}{l}\text { NO/orbit } \\
\text { disorders }\end{array}$} & all & & $\begin{array}{l}10 \\
(10.8 \%)\end{array}$ & $\begin{array}{l}5 \\
(11.6 \%)\end{array}$ & $\begin{array}{l}5 \\
(10.0 \%)\end{array}$ \\
\hline & neuritis & $\mathrm{H} 46$ & $\begin{array}{l}3 \\
(3.2 \%)\end{array}$ & $\begin{array}{l}2 \\
(4.7 \%)\end{array}$ & $\begin{array}{l}1 \\
(2.0 \%)\end{array}$ \\
\hline & AION & $\mathrm{H} 47.0$ & $\begin{array}{l}6 \\
(6.5 \%)\end{array}$ & $\begin{array}{l}3 \\
(7.0 \%)\end{array}$ & $\begin{array}{l}3 \\
(6.0 \%)\end{array}$ \\
\hline & infection & $\mathrm{H} 04.3$ & $\begin{array}{l}1 \\
(1.1 \%)\end{array}$ & 0 & $\begin{array}{l}1 \\
(2.0 \%)\end{array}$ \\
\hline \multirow[t]{3}{*}{$\begin{array}{l}\text { IOP } \\
\text { disorders }\end{array}$} & all & & $\begin{array}{l}5 \\
(5.4 \%)\end{array}$ & $\begin{array}{l}1 \\
(2.3 \%)\end{array}$ & $\begin{array}{l}4 \\
(8.0 \%)\end{array}$ \\
\hline & IOP decompensation & $\mathrm{H} 40.5$ & $\begin{array}{l}4 \\
(4.3 \%)\end{array}$ & $\begin{array}{l}1 \\
(2.3 \%)\end{array}$ & $\begin{array}{l}3 \\
(6.0 \%)\end{array}$ \\
\hline & bleb infection & H59.8 & $\begin{array}{l}1 \\
(1.1 \%)\end{array}$ & 0 & $\begin{array}{l}1 \\
(2.0 \%)\end{array}$ \\
\hline others & all & & 7 & 4 & 3 \\
\hline
\end{tabular}




\begin{tabular}{|c|c|c|c|c|}
\hline trauma & $\begin{array}{l}\text { S05.8, S05.2, } \\
\text { S05.3, T26.6 }\end{array}$ & $\begin{array}{l}4 \\
(4.3 \%)\end{array}$ & $\begin{array}{l}2 \\
(4.7 \%)\end{array}$ & $\begin{array}{l}2 \\
(4.0 \%)\end{array}$ \\
\hline uveitis & $\mathrm{H} 15.0, \mathrm{H} 22.1$ & $\begin{array}{l}2 \\
(2.2 \%)\end{array}$ & $\begin{array}{l}2 \\
(4.7 \%)\end{array}$ & 0 \\
\hline other & T85.3 & $\begin{array}{l}1 \\
(1.1 \%)\end{array}$ & 0 & $\begin{array}{l}1 \\
(2.0 \%)\end{array}$ \\
\hline
\end{tabular}

AION: anterior ischemic optic neuropathy; AMD: age-related macular degeneration; IOP: intraocular pressure; NO: neuro-ophthalmology; RAO: retinal artery occlusion; RVO: retinal vein occlusion

Patients were asked for relevant preexisting medical conditions. Three out of four patients (72 of 93, $77.4 \%$ ) indicated at least one comorbidity. Systemic arterial hypertension was the most common comorbidity and was reported in more than every second patient. Only a minority of patients had pulmonary disease, while every fifth patient was under treatment for a disorder of the heart (see Table 3).

Table 3

medical history of study group.

\begin{tabular}{|llll|}
\hline & total study group & before April 20th & from April 20th \\
\hline diabetes & $14(5.1 \%)$ & $5(11.6 \%)$ & $9(18.0 \%)$ \\
\hline systemic arterial hypertension & $49(52.7 \%)$ & $19(44.2 \%)$ & $30(60.0 \%)$ \\
\hline pulmonary disease & $7(7.5 \%)$ & $4(9.3 \%)$ & $3(6.0 \%)$ \\
\hline heart disease & $19(20.4 \%)$ & $7(16.3 \%)$ & $12(24.0 \%)$ \\
\hline smoking & $23(24.7 \%)$ & $10(23.3 \%)$ & $13(26.0 \%)$ \\
\hline other & $32(34.4 \%)$ & $19(44.2 \%)$ & $13(26.0 \%)$ \\
\hline at least 1 comorbidity & $72(77.4 \%)$ & $35(81.4 \%)$ & $37(74.0 \%)$ \\
\hline reduced mobility & $17(18.5 \%)$ & $8(18.6 \%)$ & $9(18.0 \%)$ \\
\hline
\end{tabular}

\section{From symptoms to ophthalmological assessment}

The majority of patients ( 85 of $93,91.4 \%$ ) stated that from their estimate the corona pandemic did not lead to a delay in regard to their way to the tertiary center. Only eight patients acknowledged that the pandemic caused a delay to some extent. There was no statistically significant difference between the two subgroups before April 20th and from April 20th $(p=0.279)$.

Most patients were referred to the tertiary center by their ophthalmologist ( 75 of $93,80.6 \%$ ), though the rate was significantly lower in the group from April 20th onward (39 of 43 vs. 36 of 50, $p=0.034$ ). While referrals by the general physician ( 1 vs. $3, p=0.623$ ) or the telephone hotline of the Regional Association of Statutory Health Insurance Physicians (Kassenärztliche Vereinigung, 2 vs. 3, $p=1.00$ ) were rare and 
distributed equally between groups, the fraction presenting without any contact to a referral doctor was significantly higher after April 20th (1 vs. 8, $p=0.036)$.

The majority of patients explained that their symptoms were stable or becoming worse in their waiting time for an appointment $(93.5 \%, 87$ of 93$)$. The rate of patients with deteriorating symptoms was higher in the group after April 20th (39.5\% vs $60 \%, 17$ of 43 vs 30 of $50, p=0.049)$. Five patients stated, that they encountered problems on their way to the tertiary center. Four patients in the before April 20th group indicated problems with getting an appointment at the center (1), getting an appointment with the referral ophthalmologist (2), and "other reasons" (1). One patient after April 20th indicated "other reasons".

\section{Subjective evaluation of barriers during SARS-CoV2 pandemic}

Almost 75\% patients expressed that they were not or not at all afraid of a SARS-CoV2 infection. 24 of the included 93 patients, however, were at least partially concerned. Similarly, 28 patients were at least partially concerned that they would be at a higher risk for an infection during their treatment at the study center. There was a statistically significant positive correlation between fear of infection and the presumption of a higher likelihood of infection at the study center $(r=0.445, p<0.001)$. Fourteen patients $(15.1 \%)$ were partially or rather concerned of difficulties in arranging appointments for follow-up care with their referral eye doctor.

Only a minority of patients indicated problems in arranging an appointment at the tertiary center (2 of 93 patients), in arranging transport to the treatment center (5 patients) or finding someone to accompany them for the examination (5 patients). The distribution of answers is shown in Fig. 1.

There was no statistically significant difference between the two subgroups before and after April 20th in any of these questions. The group before April 20th tended to expect more problems in the follow-up care, though statistical significance was not met (Wilcoxon $p=0.0828)$.

Age was associated with statistically significantly lower subjective fear or infection (Spearman correlation coefficient -0.218 , p-value 0.034 ), and less concerns regarding problems with follow-up care (corr. coefficient $-0.305, p=0.003$ ). In addition, patients of higher age were less likely to expect problems with transport $(-0.306, p=0.003)$ or in finding someone to accompany (corr. coefficient $-0.252, p=$ 0.015). There were no differences concerning problems in scheduling appointments at the eye doctor and the tertiary center, respectively (corr. coefficient $-0.091, p=0.39$, and $-0.14, p=0.181$ ), or the risk for an infection at the hospital (corr. coefficient $-0.104, p=0.324$ ).

Patients with comorbidities tended to be more likely to be afraid of a COVID infection (corr. coefficient $0.183, p=0.0785$ ) and were significantly more likely concerned about problems with organizing follow-up care (corr. coefficient $0.222, p=0.0328$ ). There was no difference concerning their considerations on likelihood of an infection in the hospital $(0.0992, p=0.347)$. 


\section{Discussion}

In this questionnaire study, we investigated patients' attitude, fears and subjective barriers in regard to receiving care for urgent ophthalmologic diseases in a tertiary center in Germany. We included patients with an acute need for treatment as an inpatient, regardless of whether surgery was indicated or not. This has to be considered when comparing the numbers from this setting to other studies reporting on emergency department visits $(8,9)$ or ophthalmic surgical care $(10)$.

Due to changes in the institutional guidelines, which allowed elective surgery again after April 20th, we divided our study group into two subgroups around April 20th .

Generally, the majority of the included patients did not report significant difficulties reaching either their referral ophthalmologist or the hospital. Only eight of the included 93 patients stated, that the pandemic led to a significant delay from their decision to visit an ophthalmologist to the actual examination. During the course of the pandemic, however, a significantly higher ratio of patients utilized our institutions emergency unit directly without a referral by their ophthalmologist. In this group also patients had a higher likelihood of a subjective deterioration of symptoms. This might reflect difficulties in scheduling timely appointments with their referral ophthalmologist.

Other studies reported a sub-average utilization of emergency departments not only in ophthalmology (8, 9), but also in other areas like dentistry (11) or general emergency units (12). Patients' attitudes or subjective barriers have not been reported, though.

Retinal disorders were the most common cause for referral, with more than $60 \%$ of the cases. Within this group, retinal detachments were the most common singular cause with $41.9 \%$, followed by retinal vessel disorders (12.9\%). Comparable figures for retinal detachments have been reported from a tertiary center in the USA (10). Corneal disorders and neuro-ophthalmologic diseases followed with $14.0 \%$ and $10.8 \%$, respectively. While these numbers were not compared to pre-pandemic times in our study, they reflect the orientation of the tertiary center with a focus on the treatment of vitreoretinal disease.

A group from the UK found evidence for more progressed retinal detachments (characterized by a higher rate of macula-off situations and PVR) during the pandemic compared to pre pandemic levels (13). In the presented study, patients did not report a delayed treatment, as reported above. Severity of RD in our collective was not assessed. As indicated above, however, a significantly higher percentage of patients in our study group indicated that their symptoms deteriorated during the course of the pandemic $(39.5 \%$ before vs. $60 \%$ after April 20 th, $p<0.05$ ). We could not assess severity of RD within our study group.

Similar trends have been reported in other surgical areas. For example, a group from Scotland presented evidence for more progressed cases of appendicitis in a district general hospital, defined as a higher severity and the increased need for surgery (14). A group from Italy, where COVID-19 hit exceptionally hard in early 2020 , reported that in up to $40 \%$ of non-traumatic emergency cases treatment was unusually delayed (15). Another group from Italy reported about a delay in treatment in 12 children with acute 
diseases, resulting in the need of intensive care in 6 patients and death in 4 of these patients (16). The reasons for the reported delays cannot be entirely elucidated. Contributing factors may be associated with different complexes, such as the patients' attitudes (e.g. fear of infection), institutional guidelines (e.g. limited access to emergency units, general physicians), or governmental regulations (lockdown).

In our study, at least every fourth patient was afraid of COVID-19, and 30\% of patients were concerned that they had a higher likelihood of infection at the treatment center. There was no difference in regard to the two subgroups before and after April 20th. Patients with systemic comorbidity or preexisting health conditions tended to be more afraid of an infection and were more likely to expect problems in the followup care. Compared to a study investigating a representative sample of US adults, which reported an average of nearly 7 in a scale of 10 for fear (17), the patients in our study appeared less concerned. This may correlate with the time of survey, as well as with the extent of the pandemic in Germany and the USA. Figures were generally lower in Germany compared to the US during the first wave of the pandemic. Additionally, the patients in our study had an urgent medical ophthalmologic disease, which may also change the perception of personal risk, compared to a randomly selected study group.

In this study, higher age was negatively correlated with fear of infection itself and the risk for infection in the hospital. Similar findings were reported in an online survey of residents of Hong Kong (18), where out of the sociodemographic factors investigated, only younger age was statistically significantly correlated with a higher concern of becoming infected in a multivariate analysis. This study, however, did not find an association of a lower perceived personal risk with less careful behaviour (e.g. hand-washing, avoidance of public gatherings) in the older patients. A national survey in the US done in March 2020 also reported a generally more optimistic outlook and better mental health in older patients, except the perceived infection-fatality risk (19). Still, protection of high-risk groups, such as patients aged 65 or older, should be protected, and the health care providers should establish protocols minimizing contacts of patients at risk, either with health care providers or other patients $(3,20,21)$.

The presented study has some limitations which have to be considered. Patient recruitment was in part performed retrospectively, and due to the design of the study especially patients in the pre April 20th subgroup were interviewed via telephone.

Some patients eligible for the study did not sign informed consent and could not be included.

Of note, institutional or national guidelines in which patients should be treated as inpatients may differ and could hinder comparability of the provided numbers with other countries or health systems. Patients who did not visit their ophthalmologist or referred to our emergency unit at all could not be included.

\section{Conclusion}

This study analyzed the patient's perspective on barriers on their way to treatment of urgent ophthalmic diseases during the early phase of the SARS-CoV-2 pandemic in Germany. Generally, most patients encountered no problems on their way to our tertiary ophthalmology center. However, about one third of patients was afraid of a COVID-19 infection, and saw a potentially higher risk for infection at the center. 
Fear of infection was significantly less dominant in older patients, although mortality is higher in this group. Efforts have to be made to reduce risk of infection in higher risk groups.

\section{Abbreviations}

Corr. Coefficient: correlation coefficient

COVID(-19): coronavirus disease (2019)

PVR: proliferative vitreoretinopathy

RRD: rhegmatogenous retinal detachment

SARS-Cov-2: severe acute respiratory syndrome, coronavirus 2

WHO: world health organization

\section{Declarations}

Ethics approval and consent to participate: The study was approved by the ethics committee of the medical faculty of the Universität Kiel, Germany. The study was performed in accordance with the ethical standards as laid down in the 1964 Declaration of Helsinki and its later amendments. All included patients signed informed consent.

Consent for publication: not applicable.

Availability of data and material: The datasets generated and/or analyzed during the current study are not publicly available due to data protection guidelines, but can be provided by the corresponding author if needed.

Competing interests: $\mathrm{CE}$ received fees for advisory boards by Bayer Vital $\mathrm{GmbH}$ and presentation fees by Allergan $\mathrm{GmbH}$, non of which interfere with the conception, conduction or analysis of the presented study. $\mathrm{CM}, \mathrm{ML}, \mathrm{AK}$ and JR declare no conflicts of interest.

Funding: The authors did not receive support from any organization for the submitted work.

Authors' contribution: CE and JR contributed to the study conception and design. Patient identification and inclusion and data collection were performed by $C E, M L, A K$ and $C M$. Analysis and writing of the first manuscript draft were performed by $\mathrm{CE}$, and all authors commented on previous versions of the manuscript. All authors read and approved the final manuscript.

Acknowledgements: We would like to thank Frau Josefin Kohn for conducting the telephone interviews.

\section{References}


1. Immovilli P, Morelli N, Antonucci E, Radaelli G, Barbera M, Guidetti D. COVID-19 mortality and ICU admission: the Italian experience. Crit Care Lond Engl. 15 2020;24(1):228.

2. Carenzo L, Costantini E, Greco M, Barra FL, Rendiniello V, Mainetti M, u. a. Hospital surge capacity in a tertiary emergency referral centre during the COVID-19 outbreak in Italy. Anaesthesia. 2020;75(7):928-34.

3. Korobelnik J-F, Loewenstein A, Eldem B, Joussen AM, Koh A, Lambrou GN, u. a. Guidance for antiVEGF intravitreal injections during the COVID-19 pandemic. Graefes Arch Clin Exp Ophthalmol. Juni 2020;258(6):1149-56.

4. Siedlecki J, Brantl V, Schworm B, Mayer WJ, Gerhardt M, Michalakis S, u. a. COVID-19:

Ophthalmological Aspects of the SARS-CoV 2 Global Pandemic. Klin Monatsblätter Für Augenheilkd. Mai 2020;237(05):675-80.

5. Hattenbach L, Heinz P, Feltgen N, Hoerauf H, Kohnen T, Priglinger S, u. a. Auswirkungen der SARSCoV-2-Pandemie auf die ophthalmologische Versorgung in Deutschland. Ophthalmol. September 2020;117(9):892-904.

6. R Core Team. R: A Language and Environment for Statistical Computing [Internet]. Vienna, Austria: R Foundation for Statistical Computing; 2016. Verfügbar unter: https://www.R-project.org/

7. Kanda Y. Investigation of the freely available easy-to-use software „EZR" for medical statistics. Bone Marrow Transplant. März 2013;48(3):452-8.

8. Posarelli C, Maglionico MN, Covello G, Loiudice P, Cipriano A, Santini M, u. a. Ophthalmological emergencies and the SARS-CoV-2 outbreak. Di Gennaro F, Herausgeber. PLOS ONE. 1. Oktober 2020;15(10):e0239796.

9. Pellegrini M, Roda M, Lupardi E, Di Geronimo N, Giannaccare G, Schiavi C. The impact of COVID-19 pandemic on ophthalmological emergency department visits. Acta Ophthalmol (Copenh) [Internet]. Juni 2020 [zitiert 9. Dezember 2020]; Verfügbar unter: https://onlinelibrary.wiley.com/doi/abs/10.1111/aos.14489

10. Al-khersan H, Kalavar MA, Tanenbaum R, Lazzarini TA, Patel NA, Yannuzzi NA, u. a. Emergent Ophthalmic Surgical Care at a Tertiary Referral Center During the COVID-19 Pandemic. Am J Ophthalmol. Februar 2021;222:368-72.

11. Guo H, Zhou Y, Liu X, Tan J. The impact of the COVID-19 epidemic on the utilization of emergency dental services. J Dent Sci [Internet]. März 2020 [zitiert 9. Dezember 2020]; Verfügbar unter: https://linkinghub.elsevier.com/retrieve/pii/S1991790220300209

12. Lucero A, Lee A, Hyun J, Lee C, Kahwaji C, Miller G, u. a. Underutilization of the Emergency Department During the COVID-19 Pandemic. West J Emerg Med [Internet]. 24. September 2020 [zitiert 9. Dezember 2020];21(6). Verfügbar unter: https://escholarship.org/uc/item/00p3c3fm

13. Jasani KM, Ivanova T, Sabatino F, Patton N, Dhawahir-Scala F, Chew G, u. a. Changing clinical patterns of Rhegmatogeneous Retinal Detachments during the COVID19 pandemic lockdown in the North West of the UK. Eur J Ophthalmol. 17. Oktober 2020;112067212096548. 
14. Dick L, Green J, Brown J, Kennedy E, Cassidy R, Othman S, u. a. Changes in Emergency General Surgery During Covid-19 in Scotland: A Prospective Cohort Study. World J Surg. November 2020;44(11):3590-4.

15. Patriti A, Baiocchi GL, Catena F, Marini P, Catarci M, FACS on behalf of the Associazione Chirurghi Ospedalieri Italiani (ACOI). Emergency general surgery in Italy during the COVID-19 outbreak: first survey from the real life. World J Emerg Surg WJES. 24 2020;15(1):36.

16. Lazzerini M, Barbi E, Apicella A, Marchetti F, Cardinale F, Trobia G. Delayed access or provision of care in Italy resulting from fear of COVID-19. Lancet Child Adolesc Health. 2020;4(5):e10-1.

17. Fitzpatrick KM, Harris C, Drawve G. Fear of COVID-19 and the mental health consequences in America. Psychol Trauma Theory Res Pract Policy. August 2020;12(S1):S17-21.

18. Chan EYY, Huang Z, Lo ESK, Hung KKC, Wong ELY, Wong SYS. Sociodemographic Predictors of Health Risk Perception, Attitude and Behavior Practices Associated with Health-Emergency Disaster Risk Management for Biological Hazards: The Case of COVID-19 Pandemic in Hong Kong, SAR China. Int J Environ Res Public Health. 29. Mai 2020;17(11):3869.

19. Bruine de Bruin W. Age differences in COVID-19 risk perceptions and mental health:Evidence from a national US survey conducted in March 2020. J Gerontol B Psychol Sci Soc Sci. 29. Mai 2020;

20. Du H, Zhang M, Zhang H, Sun X. Practical experience on emergency ophthalmic surgery during the prevalence of COVID-19. Graefes Arch Clin Exp Ophthalmol. August 2020;258(8):1831-3.

21. Lim LW, Yip LW, Tay HW, Ang XL, Lee LK, Chin CF, u. a. Sustainable practice of ophthalmology during COVID-19: challenges and solutions. Graefes Arch Clin Exp Ophthalmol. Juli 2020;258(7):1427-36.

\section{Figures}


I fear infection with the corona virus.

I have a higher risk of infection at the hospital.

I expect difficulties with arranging follow-up care.

I had problems scheduling an appointment at the treatment center.

I had problems arranging transport to the treatment center.

I had problems in finding someone to accompany me to the center.
55,9

\section{6,3}

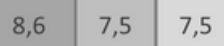

95,7

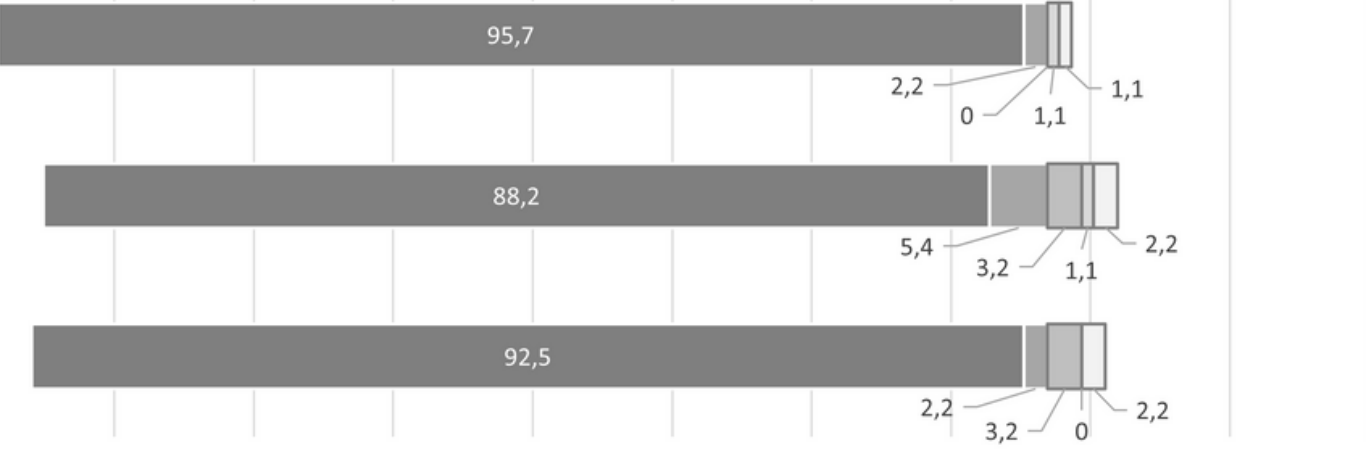

m not at all $\quad$ rather not $\quad \square$ in part $\quad \square$ rather yes $\square$ definitely yes

\section{Figure 1}

Subjective evaluation of barriers during SARS-CoV2 pandemic

\section{Supplementary Files}

This is a list of supplementary files associated with this preprint. Click to download.

- COVID19DETOURFragebogen.pdf

- COVID19DETOURquestionnaireenglish.pdf 